\title{
Putting Pain in its Proper Place
}

\author{
Kevin Reuter, Michael Sienhold, Justin Sytsma \\ Forthcoming in Analysis
}

\begin{abstract}
In a series of articles in this journal, Michael Tye (2002) and Paul Noordhof $(2001,2002)$ have sparred over the correct explanation of the putative invalidity of the following argument: the pain is in my fingertip; the fingertip is in my mouth; therefore, the pain is in my mouth. Whereas Tye explains the failure of the argument by stating that "pain" creates an intensional context, Noordhof maintains that the "in" in "the pain is in my fingertip" is not spatial, but has state-attributing character. In this paper, we offer a third account, explaining the failure of the argument through stateattributing pragmatic implicatures. Empirical evidence is provided in support of this account.
\end{abstract}

Consider the following argument, first put forward, so far as we are aware, by Block $(1983,517)$ :

The pain is in my fingertip.

The fingertip is in my mouth.

Therefore, the pain is in my mouth.

Block asserts that "the conclusion obviously does not follow" and attempts to explain why the argument fails. His view is that the predicate "in" works differently for mental particulars, like pains, than for physical objects. Other authors - most notably Tye $(1995,2002,2005)$ and Noordhof $(2001,2005)$ - have shared Block's intuition that the pain-in-mouth argument fails, but have offered competing explanations of why it fails. In this paper, we will offer a new, pragmatic diagnosis of the intuition that the pain-in-mouth argument goes wrong, contrasting this with the accounts offered by Tye and Noordhof. We then offer empirical evidence that our explanation better accounts for people's judgments concerning the pain-in-mouth argument.

\section{The Strategy}

Both Tye and Noordhof utilize the following three-step strategy to support their preferred account of the failure of the pain-in-mouth argument:

(i) introduce an analogous argument;

(ii) give an explanation why the analogous argument fails;

(iii) apply that explanation to the pain-in-mouth argument. 
Thus, according to Tye, the following is analogous to the pain-in-mouth argument:

(T1) I want to be in City Hall.

(T2) City Hall is in the ghetto.

(TC) I want to be in the ghetto.

Tye then notes that (TC) does not follow from its premises because "want" creates an intensional context. Finally, he argues that the pain-in-mouth argument fails for the same reason. Tye maintains that pains are conceived of as representational states such that "pain" creates an intensional context. ${ }^{1}$ The impact of Tye's proposal can hardly be underestimated. If he is right, then he provides substantial evidence for the view that pains are conceived of as representational states.

Although Noordhof is also in favor of a representational view of pain, he believes that Tye's explanation is mistaken and, hence, cannot be called on to support representationalism. Instead, Noordhof (2001) puts forward a different analogous argument:

(N1) There is a hole in my shoe.

(N2) The shoe is in the box.

(NC) There is a hole in the box.

This argument fails, so Noordhof contends, because there is a non-spatial sense of "in"- the state-attributing sense - that is at work in statements such as "there is a hole in my shoe." Applying step (iii) of the stated strategy, Noordhof argues that the same is true of the pain-inmouth argument: while the "in" in "the fingertip is in my mouth" is used spatially, the "in" in "the pain is in my fingertip" attributes something painful to my fingertip. Consequently, the argument can be shown to fail without positing the existence of an intensional context.

So, who has provided the right analogy? We believe that neither of the two explanations offered gets to bottom of the general intuition driving the sentiment that the argument fails, although our own account takes inspiration from both proposals. Against Noordhof (and in line with Tye) we hold that the "in" in "the pain is in my fingertip" retains its spatial meaning, but against Tye (and in line with Noordhof) we believe that the failure of the pain-in-mouth argument is explained by a state-attributing factor, namely that there is something wrong with the place in which there is a pain. However, instead of proposing a semantic solution to the problem, we argue that it is best explained through pragmatic implicatures.

\footnotetext{
${ }^{1}$ As Tye $(1995,296)$ puts the point, "one can have a pain in a finger without having a pain in the mouth even if one's finger is in one's mouth (just as one can believe that one is in Vancouver without believing that one is in Canada, even given that Vancouver is in Canada)." See also Carruthers (2000, 120).

${ }^{2}$ For further examples with a similar structure, see Noordhof (2002) and Noordhof (2005). For a similar suggestion on how to explain the failure of the pain-in-mouth argument, see Bain $(2007,198)$.
} 
In order to illustrate our account, consider the following argument that we take to be analogous to the pain-in-mouth argument:

$\left(1^{*}\right)$ There is tissue damage in my finger.

$\left(2^{*}\right)$ The finger is in my mouth.

(C*) There is tissue damage in my mouth.

In the argument, the "in" appears to have a purely spatial meaning in the premises as well as in the conclusion. Further, "tissue damage" does not create an intensional context. And, yet, we are inclined to judge that the argument fails. We contend that it fails because there is a tension between what is implicated by the two premises and what is implicated by the conclusion: the conclusion seems to carry the implicature that something is wrong with the speaker's mouth, while the premises carry no such implicature.

In order to illustrate how the conversational implicature is activated, consider $\left(\mathrm{C}^{*}\right)$. According to our account, this sentence can be true for a variety of reasons, including that the speaker has put an injured finger in her mouth or that she has injured the inside of her mouth. The Gricean maxims of relevance and manner (Grice, 1975) dictate that we should say only things that are relevant or important and we should say them in a way that is clear. In most circumstances, it would hardly be relevant for a speaker to say that she has tissue damage in her mouth if she had just put an injured finger in her mouth. And saying that there is tissue damage in her mouth would hardly be a perspicuous way to convey this state of affairs. If she has injured the inside of her mouth, however, the claim that there is tissue damage in her mouth will be both relevant and clear in most conversational settings.

Let us now consider the pain-in-mouth argument again. If we are right in claiming that the argument we presented above is analogous to the pain-in-mouth argument, then no non-spatial meaning of "in" needs to be posited to explain its failure. Nor do we need assume that "pain" creates an intensional context. The pain-in-mouth argument fails because the conclusion implicates that something is wrong with my mouth, whereas no such implicature can be derived from the premises. Accordingly, it would be wrong to classify the pain-in-mouth argument as invalid. The conclusion is not necessarily false, but simply has a misleading implicature given the two premises.

How can we decide which of these three accounts provides the best diagnosis of the failure of the pain-in-mouth argument? To answer this question, we need to consider what is being claimed when it is claimed that the argument fails. The discussions of this argument are typically phrased in terms of invalidity, which might suggest that the issue is a technical one. This is misleading, however, since whether the argument is valid or invalid depends on how we interpret the key phrases in it. As Block $(1983,517)$ notes in his original discussion of the argument, it is "valid for the 'in' of spatial enclosure." Against this, he asserts that if we suppose the premises "are true in their ordinary meanings" then "the conclusion obviously does not follow." Block's goal is then 
to draw out the ordinary meanings so as to explain why the conclusion does not follow. And, we believe, something similar is going on in Tye and Noordhof as well. ${ }^{3}$ Understood in this way, the goal of an account of the failure of the pain-in-mouth argument is to articulate the ordinary understanding of the premises and conclusion of the argument so as to diagnose the intuition that something is wrong with the argument.

Accepting the above articulation, the alternative accounts of the failure of the argument would appear to be open to empirical investigation. We can test both the underlying assumption that people will judge that the conclusion does not follow from the premises, and we can test which "analogous" arguments they make similar judgments about. In the next section, we detail three experiments testing our account against those given by Tye and Noordhof.

\section{Empirical Evidence}

One of the most heated debates in the philosophy of pain revolves around the question of whether pains are conceived of as mental or bodily states (Aydede 2005, Hill 2005). Those who promote a bodily conception of pain (Reuter \& Sytsma forthcoming, Sytsma \& Reuter 2017), often argue that the semantics of statements like "I have a pain in my shoulder" indicates that pains inhabit body parts (and not the mind). Proponents of the mental view of pain then often claim that the semantics of pain reports need to be given a different spin, e.g. Tye's proposal that "pain" creates an intensional context. Irrespective of how pains are conceived of, no one denies that people locate things like tissue damage in their body parts. Our account of the pain-in-mouth argument predicts not only that people will tend to judge that this argument fails, but that they will also tend to judge that corresponding arguments where "pain" is replaced with terms like "tissue damage" will also fail. ${ }^{4}$ Importantly, however, our account only predicts that people will judge that the argument fails when the conclusion misleadingly suggests that there is something wrong with the speaker's mouth. For example, if "pain" is replaced with "paper-clip," we predict that people would tend to accept the conclusion since it would not seem to imply that there is anything wrong with the speaker's mouth.

To test these predictions, in our first study we gave participants one of four arguments - either a version of the pain-in-mouth argument, or a variation in which "pain" is replaced with

\footnotetext{
${ }^{3}$ For instance, Tye $(2000,35)$ treats the failure of the pain-in-mouth argument as one of "a clear range of commonsense facts that any theory of phenomenal consciousness needs to explain." Against this there is a growing series of results suggesting that many of the commonsense facts that philosophers have claimed about phenomenal consciousness are not in fact commonsense (e.g., Sytsma \& Machery 2010; see Sytsma 2014a for discussion and Sytsma \& Buckwalter 2016, Part IIC and Sytsma 2014b for further examples of work in the area), including a number of claims that have been made about pains (e.g., Sytsma 2010, Reuter 2011, Reuter et al. 2014).

4 "Tissue damage" is an especially relevant comparison, since Tye argues that feelings of pain represent tissue damage (e.g, 2005, 100-101; 1997, 125).
} 
"inflammation," "tissue damage," or "paper-clip":

The (pain/tissue damage/inflammation/paper-clip) is (in/on) my fingertip.

The fingertip is in my mouth.

Therefore, the (pain/tissue damage/inflammation/paper-clip) is in my mouth.

Participants were then asked to indicate how much they agreed or disagreed with the conclusion of the argument using a 7-point Likert scale anchored at 1 with "Strongly Disagree," at 4 with "Neither Agree nor Disagree," and at 7 with "Strongly Agree." Responses were collected from 174 participants using Amazon Mechanical Turk. ${ }^{5}$ As predicted, we found that while most participants disagreed with the conclusions for pain $(\mathrm{M}=2.43)$, tissue damage $(\mathrm{M}=2.53)$, and inflammation ( $M=2.86)$, most participants agreed with the conclusion for paper-clip $(M=6.10)$. The mean values for "pain," "tissue damage," and "inflammation" were all significantly below the midpoint, whereas the mean value for "paper-clip" was significantly above the midpoint. ${ }^{6}$ The results are depicted in Figure 1 below.

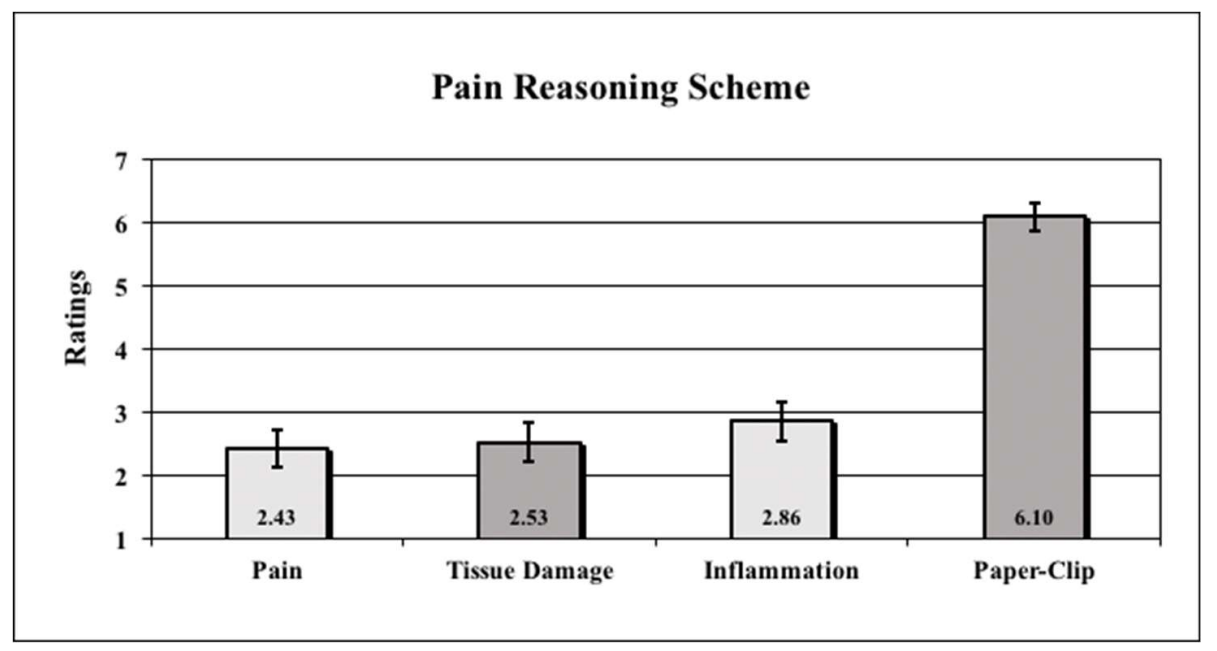

Figure 1: Average results of the reasoning experiment for "pain," "tissue damage," "inflammation," and "paper-clip". Bars indicate standard errors around the means.

\footnotetext{
${ }^{5}$ Participants were $54.0 \%$ women, with an average age of 36.6 years.

${ }^{6}$ Pain: $\mathrm{t}(43)=-5.44, \mathrm{p}<0.001$; tissue damage: $\mathrm{t}(44)=-4.67, \mathrm{p}<0.001$; inflammation: $\mathrm{t}(43)=-3.69, \mathrm{p}<0.001$; paper-clip: $\mathrm{t}(40)=10.038, \mathrm{p}<0.001$. Pairwise comparisons (Bonferonni-corrected) yielded no significant differences both between pain and tissue damage $(\mathrm{t}(86.512)=-0.23, \mathrm{p}=.812)$, on the one hand, and pain and inflammation $(\mathrm{t}(85.62)=-1.02, \mathrm{p}=0.308)$, on the other. The three comparisons with paper-clip were all significant (all p-values $<0.001$ ). There is some debate about whether it is appropriate to analyze Likert items using parametric tests. (Thanks to an anonymous reviewer for raising this concern.) While we believe that the use of t-tests is unlikely to cause serious problems in cases like this, we also analyzed the results using a non-parametric test. Wilcoxon signed rank tests confirmed the above findings, rejecting the hypotheses that the central tendency for pain ( $V=126.5, p<0.001)$, tissue damage ( $V=167, p<0.001)$, and inflammation $(\mathrm{V}=219.5, \mathrm{p}<0.001)$ were greater than or equal to 4 , and rejecting the hypothesis that the central tendency for paper-clip was less than or equal to $4(\mathrm{~V}=724.5, \mathrm{p}<0.001)$.
} 
The results of our first study indicate that people do in fact tend to view the original pain-inmouth argument as failing. But they also tend to view the two arguments featuring bodily states — inflammation and tissue damage — as failing. Furthermore, the data from the paper-clip variation reveals that in uncontroversial cases with no misleading implications, the spatial reasoning scheme is accepted by almost everybody. These results are directly predicted by our account, but are not obviously predicted by either Tye's account or Noordhof's account. If the problem with the pain-in-mouth argument was simply that "pain" creates an intensional context, we would expect people to accept the arguments for "tissue damage" and "inflammation" since these do not create intensional contexts. Alternatively, if the problem was simply that "in" is used in a non-spatial sense in the first premise of the pain-in-mouth argument, we would again expect people to accept the arguments for "tissue damage" and "inflammation" since the "in" in these arguments would seem to be straightforwardly spatial. But they don't.

It should be noted, here, that these results do not necessarily show that the pain-in-mouth argument does not suffer from the problems that Tye and Noordhof identify. It is, of course, possible that one argument could go wrong in multiple ways. And it is possible that different people could find that an argument went wrong for different reasons. What the results do suggest, however, is that something further is going on here. The fact that people also reject versions of the argument where Tye's and Noordhof's explanations do not clearly apply, and do so to a roughly equal degree, indicates that a further explanation is called for. And our account provides just such an explanation.

There are two primary objections that might be raised against the positive support we've offered for our explanation of the failure of the pain-in-mouth argument. First, it might be objected that "on" does not work the same as "in" in these arguments, such that the comparison case of "paperclip" is simply irrelevant. And absent a case in which people accept the relevant reasoning schema when the conclusion is not misleading, we have not adequately tested our explanation. ${ }^{7}$ Second, it might be objected that while we have tested the extent to which the conclusions of the arguments are rejected in the first study, we relied on our own sense of how misleading the four conclusions were. Consequently, we cannot infer that the extent to which the conclusions are rejected corresponds with lay judgements about how misleading they are.

To address these issues more thoroughly, we conducted a follow-up study in which we selected fourteen items that can reasonably be found in or on a finger: pain in, inflammation in, infection in, splinter in, broken bone in, tissue damage in, blood in, paper-clip on, cut on, nail on, perfume on, blood on, sore on, gasoline on. The study was conducted in two parts. The first part used a within-participants design to solicit judgments about how misleading the conclusion of the spatial reasoning schema was for each of these fourteen items. For each item, participants were asked the

\footnotetext{
${ }^{7}$ To alleviate this concern, we tested the suggestion of a reviewer for this journal and ran the same argument with the item serum which is in a fingertip. The average rating of 37 participants was 5.93, clearly indicating that most participants did not believe that the argument failed when no misleading implicature was present.
} 
following:

If you were told that somebody had [item] in their mouth, how misleading would you consider that statement to be if you were later told that, in fact, the person had [item in/on] their thumb and that their thumb was in their mouth?

Participants answered using a 7-point Likert scale anchored at 1 with "Very Misleading" and at 7 with "Not at All Misleading." The fourteen questions were counterbalanced for order. The second part of the study employed a between-participants design, with each member of a new set of participants being given the following prompt for just one of the fourteen items:

Susan has [item in/on] her right thumb. Susan's right thumb is in her mouth.

Participants were then asked how much they agreed or disagreed with the claim, "There is [item] in Susan's mouth," answering on a 7-point Likert scale anchored at 1 with "Strongly Disagree," at 4 with "Neither Agree nor Disagree," and at 7 with "Strongly Agree." Responses for the first part of our study were collected from 70 participants. ${ }^{8}$ Responses for the second part of the study were collected from 560 participants ( 40 per item). ${ }^{9}$ Both parts were conducted using the Philosophical Personality website (http://philosophicalpersonality.com).

The first thing to note is that the second part of our study served as a replication of our first experiment using a different source of participants. Results were comparable to those obtained in the first study for pain ( $M=2.25)$, tissue damage $(M=2.55)$, inflammation $(M=3.40)$, and paperclip (5.25). Once again, the mean response for each of the first three were significantly below the midpoint, whereas the mean value for the last was significantly above the midpoint. ${ }^{10}$

Most importantly, our account predicts that the extent to which the conclusions are accepted will inversely correlate with the degree to which the conclusion is judged to be misleading. And that is exactly what we found. Two linear regression analyses were conducted, one for the means for all items and one only using the means for the items with the preposition "in." Both correlations were highly significant. The regression line for all items is shown in Figure 2 below. ${ }^{11}$

\footnotetext{
${ }^{8}$ Participants were $54.3 \%$ women, with an average age of 31.2 years.

${ }^{9}$ Participants were $64.8 \%$ women, with an average age of 34.6 years.

${ }^{10}$ Pain: $\mathrm{t}(39)=-6.60, \mathrm{p}<0.001$; tissue damage: $\mathrm{t}(39)=-4.94, \mathrm{p}<0.001$; inflammation: $\mathrm{t}(39)=$ $-1.78, p=0.041$; paper-clip: $t(39)=3.88, p<0.001$. Wilcoxon signed rank tests confirmed the findings. Pain: $\mathrm{V}=48, \mathrm{p}<0.001$; tissue damage: $\mathrm{V}=53.5, \mathrm{p}<0.001$; inflammation: $\mathrm{V}=195.5, \mathrm{p}=0.038$; paper-clip: $\mathrm{V}=568$, $\mathrm{p}<0.001$.

${ }^{11}$ All items: $F(1,12)=104.83, p<0.001, R^{2}=0.897$. Items with "in": $F(1,5)=11.79, p=0.019, R^{2}=0.702$.
} 


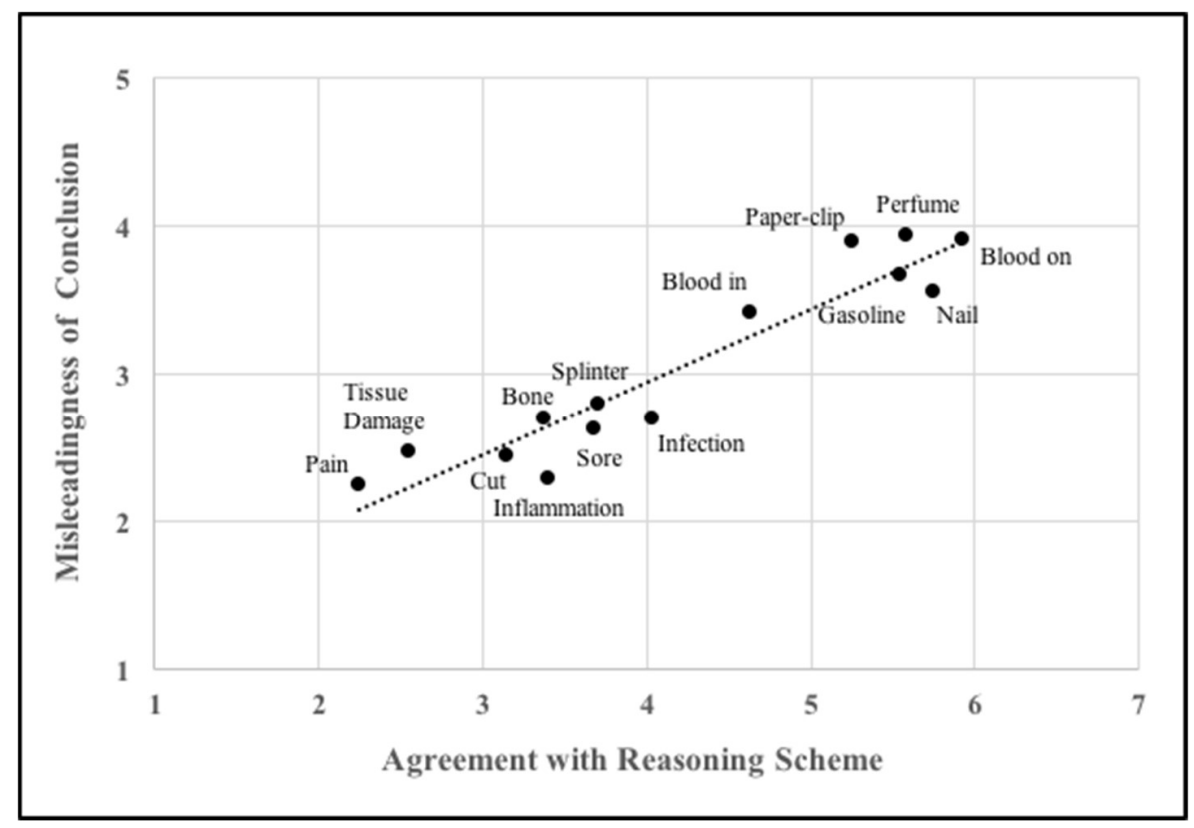

Figure 2: Regression line indicating a correlation between the means for acceptance of the reasoning scheme with the means for misleadingness of the conclusions for all 14 tested items.

While the results of our second experiment are consistent with our explanation, one should be wary of moving from correlation to causation. The results do not establish that the arguments are rejected because the conclusions are misleading. At the same time, the correlation we find calls out for explanation. And while our account predicts this finding, neither Tye's account nor Noordhof's account offers a direct explanation. Further, our account explains why we would find mean agreement with the arguments falling along a spectrum-we find this because the conclusions are not equally misleading. Neither of the other two accounts readily explains this aspect of our data, since the factors they call on to explain the failure of the pain-in-mouth argument do not obviously admit of gradation. That said, it might be argued that the gradation we find in mean agreement with the arguments is a population-level phenomenon that can be explained in terms of variation in the percentage of the population that reads the relevant term as creating an intensional context or reads "in" / "on" as state-attributive for a given argument. It is unclear, however, why such variation should be expected.

Thus, given the results of our first two experiments, Occam's razor would seem to support our explanation of the pain-in-mouth argument over the competition. Nonetheless, further research is called for with regard to our positive proposal. While space prevents us from fully carrying out that research here, we want to conclude with an initial experiment directly testing our account.

If our explanation of the failure of the pain-in-mouth argument is generally correct, then we would expect agreement with the conclusion of the argument to rise if we prompt participants to ignore how the conclusion might be misleading and instead focus on whether the conclusion technically follows from the premises, such as: 
Although it might sound misleading to say that there is a pain in Susan's mouth, technically speaking there is a pain located in her mouth.

In our third study, we tested the effect of this alternative wording of the conclusion by randomly assigning 244 participants to either the original form of the argument (used in Study 2) or the argument featuring the revised conclusion as exemplified above. Participants were given one of the four lowest-rated items from our second study and asked to assess the statement using the same scale. Responses were collected using Amazon's Mechanical Turk. ${ }^{12}$ As predicted, we found that responses for each item - pain $(M=3.79)$, inflammation $(M=4.14)$, cut $(M=4.97)$, and tissue damage ( $\mathrm{M}=4.66)$ - were significantly higher compared to the mean values of the standard argument: pain $(\mathrm{M}=2.10)$, inflammation $(\mathrm{M}=2.42)$, cut $(\mathrm{M}=2.66)$, and tissue damage $(\mathrm{M}=3.21){ }^{13}$ Admittedly, the average ratings of the four tested items were still lower than for items like paperclip in our previous experiments. However, these differences likely reflect that our manipulation did not fully cancel the pragmatic implicature for all participants and/or that some participants did not recognize the technical sense of the terms suggested by the prompts. Further, since the means for all four items were depressed, there is no reason to think that this issue is specific to the pain prompt. Overall, the results of the third experiment provide further support for our account, indicating that the misleadingness of the conclusion is a significant factor in judgments that the pain-in-mouth argument fails.

\section{Conclusion}

In this paper, we have cast doubt on the two primary accounts of the failure of the pain-in-mouth argument in the existing literature. We have also offered a third proposal, suggesting that the pain-in-mouth argument is not invalid, but rather fails for pragmatic reasons. And empirical data from three experiments provides initial support for our account.

In closing, we would like to highlight that if our proposal is correct, then this paper provides support for a bodily conception of pain. Not only can the pain-in-mouth argument no longer be used to support a representationalist view of pain, the results suggest that pain is a state of the body, not of the mind. The semantics of reports like "there is pain in my fingertip," taken at face value, tells us that pains are located in body parts. Sometimes it is ok to take the semantics at face value.

\footnotetext{
${ }^{12}$ Participants were $47.2 \%$ women, with an average age of 38.4 years.

${ }^{13}$ We applied a 2 x 4 ANOVA with participants' ratings as the dependent measure and the independent factors Type with two levels (original, revised) and Item with four levels (pain, inflammation, cut, tissue damage). The analysis revealed a highly significant main effect for Type, $\mathrm{F}(1,236)=48.71, \mathrm{p}<0.001, \eta^{2}$ $=.17$, and Item, $\mathrm{F}(1,236)=3.19, \mathrm{p}=0.025, \eta^{2}=.04$. No interaction was found between Type and Item, $\mathrm{F}(1,236)=0.54, \mathrm{p}=0.659, \eta^{2}<.01$. In one sample tests, Cut $(\mathrm{t}(31)=2.55, \mathrm{p}=0.016)$ was significantly and tissue damage $(\mathrm{t}(31)=1.84, \mathrm{p}=0.074)$ was marginally significantly above the midpoint, but pain and inflammation were not.
} 


\section{References}

Aydede, M. (2005). The main difficulty with pain. In M. Aydede (ed.), Pain: New Essays on its Nature and the Methodology of its Study. Cambridge, MA: MIT Press.

Bain, D. (2007). The location of pains. Philosophical Papers, 36(2), 171-205.

Block, N. (1983). Mental Pictures and Cognitive Science. Philosophical Review, 93, 499-542.

Carruthers, Peter (2000). Phenomenal Consciousness: A Naturalistic Theory. Cambridge: Cambridge University Press.

Grice, H. (1975). Logic and conversation. In P. Cole \& J. Morgan (ed.), Syntax and Semantics, 3: Speech Acts, pp. 41-58. New York: Academic Press.

Hill, C. (2005). Ow! The Paradox of Pain. In Murat Aydede (ed.), Pain: New Essays on its Nature and the Methodology of its Study. Cambridge, MA: MIT Press.

Noordhof, P. (2001). In Pain. Analysis, 61, 95-97.

Noordhof, P. (2002). More in Pain. Analysis, 62, 153-154.

Noordhof, P. (2005). In a State of Pain. In M. Aydede (ed.), Pain: New Essays on its Nature and the Methodology of its Study. Cambridge, MA: MIT Press.

Reuter, K, Phillips, D., Sytsma, J. (2014). Hallucinating Pain. In J. Sytsma (ed.), Advances in Experimental Philosophy of Mind. London: Bloomsbury.

Reuter, K., Sytsma, J. (forthcoming). Unfelt Pain. Synthese.

Sytsma, J. (2010). Dennett's Theory of the Folk Theory of Consciousness. Journal of Consciousness Studies, 17(3/4): 107-130.

Sytsma, J. (2014a). Attributions of Consciousness. WIREs Cognitive Science, 5: 635-648.

Sytsma, J., ed. (2014b). Advances in Experimental Philosophy of Mind. London: Bloomsbury.

Sytsma, J. and W. Buckwalter, eds. (2016). A Companion to Experimental Philosophy. Malden, MA: Wiley Blackwell.

Sytsma, J., Machery, E. (2010). Two conceptions of subjective experience. Philosophical Studies 151/2: 299-327.

Sytsma, J., Reuter, K. (2017). Experimental philosophy of pain. Journal of the Indian Council of Philosophical Research, 34/3: 611-628.

Tye, M. (1995). A Representational Theory of Pains and their Phenomenal Character. In N.

Block, O. Flanagan, \& G. Guzeldere (Eds.), The Nature of Consciousness: Philosophical and Scientific Debates. Cambridge, MA: MIT Press.

Tye, M. (1997). Ten Problems of Consciousness: A Representational Theory of the Phenomenal Mind. Cambridge, MA: MIT Press.

Tye, M. (2000). Consciousness, color, and content. Cambrige, MA: MIT Press.

Tye, M. (2002). On the Location of a Pain. Analysis, 62, 150-153.

Tye, M. (2005). Another look at representationalism about pain. In M. Aydede (ed.), Pain: New Papers on its Nature and the Methodology of its Study. Cambridge, MA: MIT Press. 